\title{
THE INFLUENCE OF ABIOTIC AND ANTHROPOGENIC FACTORS ON THE FORMATION OF POTATO YIELD
}

\author{
Alexander Shpanev ${ }^{1, *}$, and Vasiliy Smuk ${ }^{1}$ \\ ${ }^{1}$ All-Russian Institute of Plant Protection, 196608 Saint-Petersburg, Russia
}

\begin{abstract}
Data on the influence of abiotic and anthropogenic factors on the formation of crop productivity are important for the productive process management system. This work examines the results of a long-term study of the influence of abiotic (weather conditions) and anthropogenic (mineral fertilizers, an integrated plant protection system) factors on the formation of potato productivity in the North-West region of the Russian Federation. Weather conditions were the most significant $(23.6 \%)$ among all the factors affecting the potato yield in the North-West region of the Russian Federation. Integrated plant protection and mineral nutrition had approximately equal contribution to the yield, i.e. $16.6 \%$ and $18.6 \%$ accordingly. In 2012 2020, additional potato yield reached $56-65 \%$ on average under the influence of mineral fertilizers, depending on their dose, and $37-56 \%$ under the influence of integrated plant protection Program. The combined influence of these two factors, taking into account the effect of interaction, led to an increase of the potato yield by $114-157 \%$ as compared with the actual yield on unfertilized and unprotected control (143 centners per hectare).
\end{abstract}

\section{Introduction}

The production process control system is based on the knowledge of rational use of abiotic, biotic and anthropogenic factors for the formation of the yield of cultivated crops. At the same time, abiotic and biotic factors affect agroecosystems in an uncontrolled mode. Abiotic factors are, first of all, weather conditions that contribute or do not contribute to the realization of the productivity potential of cultivated plants in a particular year. The influence of weather conditions on the yield of potatoes, according to literature data, ranges from 4 to $40 \%$, and in years with especially unfavorable conditions it reaches 50\% [1-3]. Among the most effective anthropogenic factors are the management of the nutrient regime through the introduction of fertilizers and the phytosanitary state of crops by means of protective measures [4]. According to the data published in the literature, the introduction of mineral fertilizers increases the yield of potatoes by $10-50 \%$, the use of plant protection products - up to $75 \%$, and in the years of strong development of diseases or mass reproduction of pests, it is much more [5-8]. Due to the combined use of mineral fertilizers and plant protection products, when the interaction effect is manifested, enhancing their separate effect, the maximum increase in potato yield is achieved [9-14].

This work examines the results of a long-term study of the influence of abiotic (weather conditions) and anthropogenic (mineral fertilizers, an integrated plant protection system) factors on the formation of potato productivity in the North-West region of the Russian Federation.

\section{Materials and methods}

The studies were carried out in the period from 2012 to 2020 at the agroecological station of the Menkovsky branch of the Agrophysical Research Institute (Leningrad Region, Gatchinsky District), which is one of the largest experimental bases with long-term fundamental researches and short-term experiments in the North-West of Russia [15].

The soil is turfy weak podzolic light loamy soils, the thickness of the arable layer is 23 centimeters, $\mathrm{pHKCl}$ is 4.6, the humus content (according to Tyurin [16]) is $1.9 \%$, mobile compounds of phosphorus and potassium (according to Kirsanov [17]) are 257 and $92 \mathrm{mg} / \mathrm{kg}$, respectively.

The agroecological station is a 7 -field grain-herbal row crop rotation in which potatoes are placed after two years of perennial grasses cultivation. Within the station three levels of mineral nutrition (MNL) - low (without fertilizers N0P0K0), medium (N65P50K50) and high $(\mathrm{N} 100 \mathrm{P} 75 \mathrm{~K} 75)$ - have been created and are maintained by a long-term annual pre-sowing introduction of azophoska and ammonium nitrate based on the planned yield of cultivated crops.

The second factor studied in the experiment was the integrated plant protection system (IPPS), according to which protective measures against pests were carried out provided that the economic threshold of harmfulness was exceeded. The integrated protection system of potato

\footnotetext{
* Corresponding author: ashpanev@mail.ru
} 
plantings consisted of seed dressing, 4 soil treatments with a rotary harrow, hilling and one-time introduction of herbicides, 3-4 treatments of vegetative plants with fungicides, desiccation.

Observations of the development of cultivated plants and the phytosanitary state of potato plantings were carried out on marked permanent registration areas of $1.4 \mathrm{~m}^{2}$, placed on the field according to the experimental scheme. Their annual number was 36, i.e. 6 for each of the experiment variants.

Statistical processing of the data obtained consisted of analysis of variance carried out in the Statistica 6.0 program.

\section{Results and discussion}

According to the data obtained, the variation in the yield of potatoes over the years ranged from 134 to $368 \mathrm{c} / \mathrm{ha}$ with an average value of 258 centner/ha. The high degree of variation was largely determined by the weather conditions of the growing season. The influence of this factor accounted for the most $-23.6 \%$, while the total contribution of abiotic and anthropogenic factors to the formation of potato yield was $76.6 \%$. Based on the identified interactions, the influence of weather conditions extended to the effects associated with the improvement of mineral nutrition and phytosanitary conditions in potato plantings (table 1). In other words, a reliable influence of weather conditions on the efficiency of the applied mineral fertilizers and the integrated plant protection system was revealed. The effect of interaction between abiotic and anthropogenic factors was expressed by 6.6 and $7.5 \%$, and their total influence was $77.7 \%$.

Table 1. Influence of abiotic and anthropogenic factors on the formation of potato productivity in the North-West of the Russian Federation (average 2012-2020).

\begin{tabular}{|l|c|}
\hline \multicolumn{1}{|c|}{ Factor } & Share, $\%$ \\
\hline Weather conditions (Year) & $23.6^{*}$ \\
\hline Mineral Nutrition Level (MNL) & $18.6^{*}$ \\
\hline Integrated Plant Protection System (IPPS) & $16.6^{*}$ \\
\hline Interactions Year + MNL & $6.6^{*}$ \\
\hline Interactions Year + IPPS & $7.5^{*}$ \\
\hline Interactions MNL + IPPS & $1.2^{*}$ \\
\hline Interactions Year + MNL + IPPS & $2.4^{*}$ \\
\hline Iteration & 1.1 \\
\hline Random & 22.3 \\
\hline Note: ${ }^{*}$ - differences are significant at P $\geq 0.95$ \\
\hline
\end{tabular}

The contribution of mineral nutrition and an integrated plant protection system turned out to be approximately equal, which accounted for 18.6 and $16.6 \%$. At the same time, in some years, the introduction of mineral fertilizers determined the value of potato yield by $58.2-75.9 \%$ and the implementation of protective measures - by $63.2-85.0 \%$. As a rule, the predominant influence of one of these factors was noted. The interaction of mineral fertilizers and plant protection products with an effect on potato yield reached 10.3$16.5 \%$ in some years or decreased to $0.4-1.0 \%$ (table 2 ).
Table 2. The influence of the main means of chemicals in the formation of potato yield in different years in the North-West of the Russian Federation.

\begin{tabular}{|c|c|c|c|}
\hline Year & $\begin{array}{c}\text { Mineral } \\
\text { Nutrition } \\
\text { Level (MNL) }\end{array}$ & $\begin{array}{c}\text { Integrated } \\
\text { Plant } \\
\text { Protection } \\
\text { System (IPPS) }\end{array}$ & $\begin{array}{c}\text { Interactions } \\
\text { MNL + IPPS }\end{array}$ \\
\hline 2012 & $21.1^{*}$ & $25.2^{*}$ & 0.4 \\
\hline 2013 & 0.3 & $85.0^{*}$ & 1.0 \\
\hline 2014 & $58.2^{*}$ & 1.3 & $5.4^{*}$ \\
\hline 2015 & $42.8^{*}$ & 0.9 & $16.5^{*}$ \\
\hline 2016 & $23.9^{*}$ & $60.4^{*}$ & 1.6 \\
\hline 2017 & $6.6^{*}$ & $63.2^{*}$ & $10.3^{*}$ \\
\hline 2018 & $36.5^{*}$ & $11.2^{*}$ & 1.4 \\
\hline 2019 & $75.9^{*}$ & 1.4 & 1.9 \\
\hline 2020 & $41.7^{*}$ & $27.8^{*}$ & $6.4^{*}$ \\
\hline Note: ${ }^{*}-$ differences are significant at P $\geq 0.95$ \\
\hline
\end{tabular}

The use of an integrated plant protection system stabilized the yield of potatoes over the years, which is confirmed by a decrease in the share of the influence of weather conditions by 1.7 times (table 3 ). At the same time, due to the improvement of the phytosanitary situation, the role of mineral nutrition increased (by 2.5 times). This confirms the advantage of the complex application of chemical agents in potato agrocenosis.

Table 3. Influence of weather conditions and mineral nutrition on the formation of potato productivity against the background of the use of an integrated plant protection system (average 2012-2020).

\begin{tabular}{|l|c|c|}
\hline \multirow{2}{*}{\multicolumn{1}{|c|}{ Factor }} & \multicolumn{2}{c|}{ Share, \% } \\
\cline { 2 - 3 } & Out IPPS & IPPS \\
\hline Weather conditions (Year) & $45.8^{*}$ & $27.7^{*}$ \\
\hline Mineral Nutrition Level (MNL) & $13.9^{*}$ & $34.8^{*}$ \\
\hline Interactions Year + MNL & $14.2^{*}$ & $7.1^{*}$ \\
\hline Iteration & 1.8 & 1.4 \\
\hline Random & 24.2 & 29.0 \\
\hline Note: ${ }^{*}$ - differences are significant at $\mathrm{P} \geq 0.95$ \\
\hline
\end{tabular}

The combined use of chemicals led to a significant increase in potato yield. According to the averaged data obtained during 2012-2020 years, the increase in potato yield under the influence of mineral fertilizers and the integrated plant protection system drew up 163.2-225.0 centner/ha, or $114-157 \%$ taking into account the interaction effect. The variation of this indicator over the years was significant and was in the range of $23-225 \%$ and $65-248 \%$, respectively, for medium - and highly fertilized variants (table 4). The strongest influence was exerted on the productive characteristics of potatoes: the mass of tubers from one plant (94-121\%) and the mass of 1 tuber $(70 \%)$. The number of tubers per plant increased under the influence of chemicals factors by $18-32 \%$, the density of productive plants - by $4-11 \%$. 
Table 4. The influence of the main means of chemicals on the formation of potato yield in the North-West region of the Russian Federation.

\begin{tabular}{|c|c|c|c|c|c|c|}
\hline \multirow{3}{*}{ Year } & \multicolumn{6}{|c|}{ Increase in yield } \\
\hline & \multicolumn{2}{|c|}{ from fertilizers } & \multicolumn{2}{|c|}{$\begin{array}{c}\text { from } \\
\text { pesticides }\end{array}$} & \multicolumn{2}{|c|}{$\begin{array}{l}\text { from fertilizers } \\
\text { and pesticides }\end{array}$} \\
\hline & $\begin{array}{l}\text { centn } \\
\text { er/ha }\end{array}$ & $\%$ & $\begin{array}{l}\text { centn } \\
\text { er/ha }\end{array}$ & $\%$ & $\begin{array}{l}\text { centn } \\
\text { er/ha }\end{array}$ & $\%$ \\
\hline \multirow{3}{*}{2012} & $\mathrm{-a}^{\mathrm{a}}$ & - & $135.1^{\mathrm{a}}$ & 112 & $-^{\mathrm{a}}$ & - \\
\hline & $113.1^{\mathrm{b}}$ & 94 & $98.5^{b}$ & 42 & $211.6^{\mathrm{b}}$ & 176 \\
\hline & $134.7^{\mathrm{c}}$ & 112 & $111.6^{\mathrm{c}}$ & 44 & $246.3^{\mathrm{c}}$ & 205 \\
\hline \multirow{3}{*}{2013} & - & - & 111.7 & 152 & - & - \\
\hline & 1.3 & 2 & 129.2 & 173 & 130.5 & 178 \\
\hline & 0 & 0 & 145.4 & 237 & 133.5 & 182 \\
\hline \multirow{3}{*}{2014} & - & - & 0 & 0 & - & - \\
\hline & 51.9 & 35 & 13.1 & 7 & 65.0 & 44 \\
\hline & 83.1 & 56 & 52.1 & 23 & 135.2 & 92 \\
\hline \multirow{3}{*}{2015} & - & - & 0 & 0 & - & - \\
\hline & 119.0 & 42 & 0 & 0 & 63.8 & 23 \\
\hline & 74.0 & 26 & 108.0 & 30 & 182.0 & 65 \\
\hline \multirow{3}{*}{2016} & - & - & 131.6 & 110 & - & - \\
\hline & 56.8 & 48 & 196.2 & 111 & 253.0 & 212 \\
\hline & 103.6 & 87 & 176.9 & 79 & 280.5 & 235 \\
\hline \multirow{3}{*}{2017} & - & - & 117.9 & 69 & - & - \\
\hline & 0 & 0 & 185.5 & 109 & 133.7 & 78 \\
\hline & 0 & 0 & 319.4 & 187 & 279.1 & 164 \\
\hline \multirow{3}{*}{2018} & - & - & 83.0 & 72 & - & - \\
\hline & 139.7 & 121 & 42.1 & 16 & 181.8 & 157 \\
\hline & 155.7 & 135 & 111.0 & 41 & 266.7 & 231 \\
\hline \multirow{3}{*}{2019} & - & - & 27.1 & 17 & - & - \\
\hline & 121.7 & 76 & 66.2 & 24 & 187.9 & 118 \\
\hline & 263.9 & 166 & 0 & 0 & 252.6 & 159 \\
\hline \multirow{3}{*}{2020} & - & - & 92.2 & 92 & - & - \\
\hline & 173.4 & 173 & 52.7 & 19 & 226.1 & 225 \\
\hline & 74.0 & 74 & 175.1 & 100 & 249.1 & 248 \\
\hline \multirow{3}{*}{$\begin{array}{c}2012- \\
2020\end{array}$} & - & - & 75.8 & 53 & - & - \\
\hline & 80.5 & 56 & 82.7 & 37 & 163.2 & 114 \\
\hline & 93.0 & 65 & 132.0 & 56 & 225.0 & 157 \\
\hline
\end{tabular}

The strong influence of the integrated plant protection system on the potato yield is determined by the high harmfulness of certain pests in the conditions of the North-West of Russia. The highest effect of the integrated potato protection system implemented in our experiments was noted in the years of epiphytotic development of late blight (2013 and 2016), and the lowest - in the years of depressive development of this disease (2014 and 2015). The average value of the saved potato yield when carrying out all the necessary set of protective measures was 97 centner/ha, or $49 \%$ of the actual crop yield equal to 298 centner/ha. According to the data obtained during 2012-2020 years, the effectiveness of the integrated potato protection system increased by $19 \%$ against the background of application of high doses of mineral fertilizers.

The average long-term increase in yield from the application of mineral fertilizers was 80.5-93.0 centner/ha (56-65\%). In 2013 and 2017 the positive effects associated with the action of fertilizers were leveled out by a strong infestation of potato plantings by late blight. Protective treatments allowed to fully realize the productive potential of plants on fertilized experimental plots. Thus, the difference in the yield of fertilized and unfertilized plots against the background of an integrated potato protection system was $37-56 \%$ and was consistently observed throughout the entire period of study.

\section{Conclusion}

The strongest influence on the formation of the potato yield is exerted by weather conditions, which also extends to the effects associated with the use of mineral fertilizers and plant protection products. The total influence of anthropogenic factors (mineral nutrition and an integrated plant protection system) is estimated at $35.2 \%$, with their equal share in the formation of potato yield. The combined influence of these two factors, taking into account the effect of interaction, led to an increase of the potato yield by 163.2-225.0 centner/hectare that was $114-157 \%$ as compared with the actual yield on unfertilized and unprotected control (143 centners/hectare). The combined influence of abiotic and anthropogenic factors was $77.7 \%$.

\section{References}

1. C. Trawczyński, Infrastructure and Ecology of Rural Areas, 3, 55-67 (2009)

2. R. Kalbarczyk, Acta Agrophysica, 4, 339-350 (2004)

3. K. Rymuza, E. Radzka, T. Lenartowicz, Communications in biometry and crop science, 10, 2, 65-72 (2015)

4. V. Voropaev, A. Shpanev, P. Lekomtsev, Ya. Ilyinskaya, International Multidisciplinary Scientific GeoConference SGEM, 609-616 (2019)

5. A. Maltas, B. Dupuis, S. Sinaj, Potato Research, 61, 97-114 (2018)

6. A. Shpanev, V. Smuk, M. Fesenko, Agrochemistry, 12, 38-45 (2017)

7. A. Shpanev, M. Fesenko, V. Smuk, Agrochemistry, 1, 12-22 (2021)

8. A. Zubarev, I. Kargin, E. Gaushev, N. Perov, Achievements of science and technology of the agro-industrial complex, 9, 22-24 (2008)

9. A. Konova, L. Samoilov, Fertility 6, 2-3 (2011)

10. N. Belous, V. Shapovalov, G. Malyavko, D. Shlyk, Agriculture 2, 28-30 (2015)

11. E. Liljeroth, A. Lankinen, W. Lars, Dh.B. Dharani, E. Alexandersson, Crop Protection, 86, 42-55 (2016)

12. T. Seraya, E. Bogatyreva, Yu. Belyavskaya, M. Zhukova, Agrochemistry, 7, 34-41 (2017)

13. V. Titova, A. Chudokvasov, Russian Agricultural Science, 6, 9-12 (2018)

14. A. Shpanev, V. Smuk, M. Fesenko, Russian Agricultural Science, 4, 27-30 (2019) 
15. A. Shpanev, Modern problems of remote sensing of the Earth from space, 3, 61-68 (2019)

16. GOST 26213-91 Soil, Methods for determining organic matter (Moscow, 1992, 9)

17. GOST R 54650-2011 Soil, Determination of mobile compounds of phosphorus and potassium by the Kirsanov method in the modification of the TsINAO (Moscow, 2013, 7) 